\title{
Listening strategies instruction: effects on Hong Kong students' general strategic behaviour
}

\author{
Marta Nogueroles López
}

Correspondence:

marta.nogueroles.lopez@gmail.com; martanl@hum.ku.dk

Department of English, Germanic and Romance Studies, University of Copenhagen, Njalsgade 28, 2300

Copenhagen, Denmark

\begin{abstract}
The present article reports on a study which explores the impact of listening strategies instruction on typical strategic behaviour. Participants were 38 Hong Kong students of Spanish divided into two groups: the experimental group, who were trained in listening strategies, and the control group, who presented similar level of Spanish, needs, educational and cultural background, but did not receive such a training. The listening strategies instruction consisted in integrating the development of listening strategies into a regular course of Spanish as a foreign language. Data referring to participants' general strategic behaviour were gathered at two time points (before and after the instruction) from a researcher-designed self-report questionnaire which required students to express the frequency they employed every specific listening strategy. Results point out modest differences in general listening strategic behaviour after the strategies instruction in both groups.
\end{abstract}

Keywords: Listening comprehension, Strategies instruction, Strategic behaviour, Self-report, Questionnaire, Spanish as a foreign language

\section{Introduction}

A needs analysis questionnaire was administered to 120 students of Spanish at The University of Hong Kong with the objective of finding out what language skill they perceived to be the most problematic in the target language. Results showed that those students believed that listening was both the most difficult and the weakest skill they struggled with in Spanish as a foreign language.

Various studies suggest that strategy instruction has a positive impact on learners' listening comprehension (Cross, 2009; Graham and Macaro, 2008; Lotfia, Maftoon, and Birjand, 2016; Thompson and Rubin, 1996). Thus we decided to design and implement a listening strategies instruction aimed to help students to become more effective listeners of Spanish.

Strategy instruction refers to the teaching of strategies to learners in order to improve their learning (Oxford, 2011). Strategy instruction is based on the ideas that: 1) strategies can be learned (Oxford, 1990); 2) students are capable of becoming more independent learners (Chamot, Barnhardt, El-Dinary, and Robbins, 1999); 3) learners are more effective when they take control of their own learning (Chamot et al., 1999); and 4) effective strategy use may determine students' success (Chamot et al., 1999).

(c) The Author(s). 2017 Open Access This article is distributed under the terms of the Creative Commons Attribution 4.0 International License (http://creativecommons.org/licenses/by/4.0/), which permits unrestricted use, distribution, and reproduction in any medium, provided you give appropriate credit to the original author(s) and the source, provide a link to the Creative Commons license, and indicate if changes were made. 
There are several strategy instruction models (Chamot and O'Malley, 1994; Chamot et al., 1999; Cohen, 1998, 2011; Macaro, 2001; Oxford, 1990, 2011). In general, most of them involve finding out students' prior knowledge about strategies, presenting the strategies selected to be developed and modelling their use, using them, evaluating their effectiveness, and transferring their use to different tasks and situations. Each one of these stages helps students to become more aware of their strategy use, have a better chance to use and transfer the strategies, as well as self-monitor and self-evaluate their strategy use (Cohen, 1998).

In the field of listening, several studies have investigated the impact of strategy instruction on learners' listening comprehension. Graham and Macaro (2008), for instance, measured the effects of strategy instruction on both the listening performance and self-efficacy of the participants against a comparison group. Cross (2009) investigated the impact of listening strategy instruction on the participants' comprehension of $\mathrm{BBC}$ news videotexts. The type of participants together with the target languages of these two studies differ from ours. Students in Graham and Macaro's (2008) were 16-17 years old who had been studying French in England for 5 years; while in Cross' (2009) study, the participants were Japanese advanced-level learners of EFL (English as a foreign language) aged between 26 and 45. Both studies concluded that the respective strategy intervention programs had a positive impact on listening performance. In the study by Graham and Macaro (2008), students who underwent strategy instruction outperformed those who did not and demonstrated that they themselves recognized this improvement. In Cross' (2009), both groups made significant gains, so a significant effect in favour of the experimental group with respect to the comparison group was not evident.

A study involving listening instruction with university students is the one by Lotfia, et al. (2016). They conducted a study with 206 students divided into two levels of language proficiency (pre-intermediate and intermediate), on one hand, and into two experimental groups and one comparison group, on the other. Apart from studying whether the designed listening strategy training enhanced EFL learners' listening performance, Lotfia, et al. (2016) intended to find out whether different approaches to listening strategy training had differential effects on listening performance, as well as how participants themselves evaluated the impact of strategy training on their listening performance. Results showed, first, that both experimental groups outperformed the comparison group on a listening achievement test, and, second, that the intermediate learners in the experimental groups outperformed the pre-intermediate ones. It is worth noticing that learners expressed a positive view of the efficacy of strategy interventions.

Other intervention studies involving listening strategy instruction focused on learners' development in strategies. In this regard, (McGruddy: The effect of listening comprehension strategy training with advanced level ESL students (Doctoral dissertation, Georgetown University, Washington DC), unpublished) used a questionnaire in order to study the impact of strategy instruction on the strategies she taught, that is the ones of predicting, selective attention, and inferencing. She found improvements in the use of some of the listening strategies taught but not others (Cross, 2009).

Some years later, Vandergrift and Tafaghodtari (2010) examined the effects of a metacognitive, process-based approach to teaching second language listening over a semester in terms of both listening comprehension and metacognitive awareness of listening. The instrument they used to measure the hypothesized growth in metacognitive awareness of listening was the Metacognitive Awareness Listening Questionnaire [MALQ] (Vandergrift, 
Goh, Mareschal, and Tafaghodtari, 2006). The drawback of using MALQ is that this instrument only focuses on metacognitive strategies, and, therefore, it does refer to neither cognitive nor socio-affective strategies. Unlike Vandergrift and Tafaghodtari (2010), Chen (2009) explored learners' listening strategy development in terms of the three types of listening strategies: metacognitive, cognitive and socio-affective. To do so, she employed reflective journals in which students were asked to reflect and evaluate how they had tried to comprehend the input and what they had understood immediately after a listening activity.

In both studies, Vandergrift and Tafaghodtari (2010) and Chen (2009), the participants were university-level students and the data collection instruments (MALQ and reflective journals respectively) were completed by students right after completing a listening task. In our case, as our objective was to measure the strategies that participants normally use and considering that task types influence learners' choice of learning strategies (Oxford and Nyikos, 1989), we decided to present our questionnaire without reference to any language task.

More recently, Yeldham and Gruba (2016) examined the progress of four Taiwanese EFL learners as they participated in a course combining direct instruction of strategies with their practice embedded in the class listening texts. Similar to our strategies instruction, their listening course combined a direct approach to strategies instruction with a metacognitive approach. Task-based verbal reports were used to gain insight into the learners' listening strategies, pre- and post-instruction. The results showed how all learners developed a greater balance in their use of top-down and bottom-up strategies, mainly by selectively integrating suitable strategies from the course into their listening repertoires.

In regard to research investigating L2 listener strategy use, various studies compared the strategy use of proficient and less-proficient listeners (O'Malley, Chamot, and Küpper, 1989; Vandergrift, 1997, 2003). Graham, Santos, and Vanderplank's (2008) focused on how listening strategy use develops over time in the absence of explicit strategy training. In fact, they explored the relationship between learners' listening proficiency and strategic behaviour, and examined how this relationship developed over 6 months in two lowerintermediate learners of L2 French (one was a high scorer, while the other one, a low scorer) when there was no explicit strategy training. Like Yeldham and Gruba (2016), data on these two learners' strategic behaviour were gathered from verbal reports made by learners while they were completing a multiple-choice listening task. Results of Graham et al.' (2008) study show a high degree of stability of strategy use over the time period, with pre-existing differences between the high and low scorer persisting. Both studies, Graham et al. (2008) and Yeldham and Gruba (2016), focus mainly on individual learners and thus they both involved a very small sample of participants.

Unlike Graham et al. (2008), we did conduct a listening strategies instruction; that is why our study is in the line of (McGruddy: The effect of listening comprehension strategy training with advanced level ESL students (Doctoral dissertation, Georgetown University, Washington DC), unpublished) and Vandergrift and Tafaghodtari (2010). Nevertheless, unlike them, our study focuses on the effect of the implemented instruction on all the strategies included in the classification of learning strategies developed by O'Malley and Chamot (1990) and adapted to listening by Vandergrift (1997), Flowerdew and Miller (2005), and Vandergrift and Gogh (2012).

Moreover, our study differs from the mentioned above in the target language. As a consequence, the present study serves to expand the field of strategies instruction applied to Spanish as a foreign language. 


\section{Methods}

The present is an intervention study which investigates the impact of actively teaching about listening strategies on the general strategic behaviour of a group of students of Spanish at The University of Hong Kong. By general strategic behaviour we mean learners' typical strategy use, that is the strategies that they normally use regardless of any specific language task. In other words, we intend to learn about the frequency of the students' strategic approaches rather than their strategic response to a given task or situation.

The study is intended to address the following research question:

- How the frequency of typical strategic behaviour develops after the course of the strategies instruction in each one of the two groups who represent the population of the study?

To answer such a research question, an intra-group comparison between the initial and the final general strategic behaviour in each one of the two groups will be made. Data regarding students' general strategic behaviour will be gathered before and after the instruction from a questionnaire which requires students to report the frequency they used each listening strategy.

Participants in this study are 38 learners of Spanish at The University of Hong Kong who were registered in sub-groups of intact classes of the course SPAN2001-Spanish II (corresponding to a level of Spanish B1 or lower-intermediate), who agreed to participate in such a study and, consequently, signed the corresponding consent form. The course SPAN2001-Spanish II lasted for one semester which consisted of 13 weeks of instruction. Depending on the sub-group students registered in, they were classified into two groups: the experimental group, who were taught by the teacher-researcher and were trained in listening strategies during this one semester, and the control group, who presented similar level of Spanish, needs, educational and cultural background, but were taught by another teacher in the Spanish Section and did not receive any strategies training. Both groups were taught Spanish using the same textbook (Martín Peris and Sans Baulenas, 2004), and identical oral materials. In this way, the two groups only differed in their methodological approach to listening comprehension. While the control group was taught the target skill by means of listening to the audio files and completing the tasks included in the textbook; the experimental group received a listening strategies instruction in which listening strategies were woven into regular class activities on a normal basis. Such an experimental model of listening instruction implied the design, piloting, fine-tuning, and implementation of a listening strategies instruction.

\section{Listening strategies instruction}

The instruction presented in this article is the result of a pilot phase which was aimed to test the exploratory model of instruction, identify aspects that somehow could be improved, and make the proper adjustments in order to obtain a refined model of instruction. After this pilot phase, the design and development of the final instruction implied making decisions about some relevant issues such as type of instruction, selection of strategies, and structure. 


\section{Type of instruction}

Our listening strategies instruction was integrated into regular classes of Spanish as a foreign language and into course materials, because, according to most research, learning strategies in context is more effective than learning them separately, as the former promotes transfer of strategy use to other similar tasks (Chamot, 2004).

Our instruction was informed as we made learners aware of specific strategies, demonstrated how they might be useful, and then provided conscious practice in using those strategies. We opted for an informed instruction instead of for an embedded or blind one, because we agree with Wenden (1987) in that the latter may not make learners aware of the strategies they are using, and, therefore, decrease the chances of both independent use and development of autonomous learning.

Finally, the listening strategies instruction we developed was directed by the teacher, since she was the one in charge of selecting materials, tasks, and strategies according to students' needs and interests, as well as of promoting independent and autonomous learning.

\section{Selection of strategies}

We opted for O'Malley and Chamot's (1990) classification of learning strategies, and, more specifically, for Vandergrift's (1997), Flowerdew and Miller's (2005), and Vandergrift and Gogh's (2012) adaptation of such a classification to listening. This taxonomy differentiates between metacognitive, cognitive, and socio-affective strategies. Each of the main three broad groups includes various types and sub-types of strategies. As many specialists (like Lynch, 2009) recommend to choose a certain number of strategies to be fully taught during the instruction, we decided to select a specific number of listening strategies to be directly and explicitly included in our instruction. The strategies that were selected to be explicitly included in the instruction were the metacognitive strategies of planning (comprehension task checking, focusing attention and global prediction), monitoring (logical monitoring and monitoring between parts), and evaluation (self-evaluation and problem identification); the cognitive strategies of elaboration and inferencing, and the socio-affective strategies of questioning for clarification and cooperation. As recommended by Graham and Macaro (2008), the selected strategies were taught in clusters.

The specific strategies were chosen according to the task, their ability to be transferred to other tasks, skills and contexts, and their empirical support. Firstly, tasks were created on the basis of the textbook's oral materials (recorded conversation, messages, stories, etc.) in a way that the resulting tasks promoted the development of relevant strategic behaviour. Secondly, the strategies we picked could be used in other tasks and learning situations in order to enhance meaningful practice and expansion of use. Thirdly, the selected strategies were considered effective by many experts like Pica (1991), Vandergrift and Goh (2012), and White (2008).

\section{Structure}

After considering the models of strategy instruction proposed by Chamot and O'Malley (1994) and Chamot et al. (1999), our listening strategies instruction was structured in three cycles, each dedicated to a group of strategies (metacognitive, cognitive, and socio-affective). Each one of the cycles consists of six phases intended to develop strategic behaviour: 1) awareness-raising; 2) presentation; 3) planning, practice, monitoring and evaluation I; 4) planning, practice, monitoring and evaluation II; 5) planning, practice, monitoring and evaluation III; and 6) expansion. 
The first one, the awareness-raising phase, was aimed to make students aware of the importance and effectiveness of using the selected listening strategies. The second phase, the presentation step, was intended to encourage students to learn the name, objective, procedure and context of use of such strategies. These introductory steps were followed by three phase of listening strategies practice orchestrated by metacognition. The reason why we included three phases devoted to practice instead of only one is because we intended to increase the opportunities of scaffolded and self-assessed practice in order to promote students' comprehension of strategies' definitions and procedure and, consequently, their conscious development. All listening strategies tasks were followed by self-assessment activities in which students were asked to reflect about the listening difficulties they encountered, the strategies they deployed to face such difficulties and, more important, about the effectiveness (or lack of it) of the employed strategies. In phase 3 (planning, practice, monitoring and evaluation I), explicit instructions and checklists guided and scaffolded the development of the target strategies. In phase 4 (planning, practice, monitoring and evaluation II), scaffoldings were being reduced, while in phase 5 , students were encouraged to select what strategies they preferred to use considering the task and its objective, as well as their personal strategies repertoire. Additionally, in this planning, practice, monitoring and evaluation III, self-assessment was promoted by means of an open-ended instrument such as a learning diary. Finally, the sixth and final phase, the expansion one, focused on transferring strategic behaviour to other tasks and skills.

In general, the instructional language was the target language, that is, Spanish. However, in some specific moments, especially in the presentation phase, the teacher used English with the objective of easing and promoting comprehension of theoretical terms and procedures related to strategies. In respect to self-assessment activities and considering that the purpose of such activities was not to produce written Spanish, but to reflect on their listening strategies performance, students were given freedom of language choice so they could decide whether they preferred to write either in the target language, Spanish, or in the language of instruction at The University of Hong Kong, English.

\section{Materials}

Five written worksheets were developed and submitted to students in the experimental group along every textbook unit with the purpose of serving as permanent information about listening strategies. Such worksheets included:

a) Awareness-raising activities in which the teacher encourage the students to reflect on the frequency they use certain strategies in their daily life (such as the strategy of monitoring while making up or shaving) as well as on the importance or effectiveness of using certain strategies (such as the strategy of questioning for clarification in a drawing dictation in which one group is allowed to ask for clarification and the other is not).

b) Theoretical explanations about the target strategies focusing on their name, definition, aims, procedure of use, and images evoking their use. The teacher models the use of the target strategies through think-aloud procedures.

c) Listening tasks created on the basis of the oral material provided by the textbook Gente 2 (Martín Peris and Sans Baulenas, 2004) with the aim of promoting the 
development of appropriate listening strategies. Considering that there are three phases devoted to practice, listening tasks vary depending on the instruction phase they refer to. Instructions in the first phase of practice are more explicit and the development of the target strategies is more guided and scaffolded. Tasks in the second phase of practice are still scaffolded, but a bit less than the ones presented in the previous phase. In the third phase of practice, students are reminded of the strategies they can apply given a specific task, but they are individually responsible for selecting which ones they prefer to employ depending on how effective they were in early encounters.

d) Transcripts of all listening materials taken from the textbook Gente 2 (Martín Peris and Sans Baulenas, 2004).

e) Self-assessment activities, including checklists (in which students tick the strategy they used right after a listening task) and learning diaries (in which students write about the difficulties they faced during the task, the strategies they employed and their effectiveness).

These worksheets helped learners to better understand strategies' aims, procedures, and contexts of use. Students completed most of these worksheets in class and only a few at home (as homework) during the course of the textbook unit and, at the end of it, they submitted them back to the teacher, so she could provide students with feedback about their listening performance, auditory problems, and strategic behaviour.

\section{Data collection method}

A self-report questionnaire was designed, tested, developed, administered, and analysed with the purpose of collecting data on students' general strategic behaviour at two time points, pre- and post-instruction. In this questionnaire, learners expressed the frequency they employed every specific listening strategy.

The selection of such a data collection measure was made, according to Cohen (2011), by taking into account concerns about the aims of the study, reliability and validity, available time and resources.

The process of designing the questionnaire required to make decisions about the questionnaire type, response type and computer coding, language, degree of formality, wording and writing, degree of dependency on a given task, triangulation, testing, and setting of administration.

First, we decided to write a self-report questionnaire. In this type of verbal report measure, learners react to typical or general statements of what they do, that is, of what strategies they frequently employ.

Second, we relied on existing questionnaires, especially on the "Strategy Inventory for Language Learning" [SILL] (Oxford, 1990), and the "Metacognitive Awareness Listening Questionnaire" [MALQ] (Vandergrift et al., 2006). The former intends to provide a general picture of the individual learners' typical strategy use, and according to White, Schramm, and Chamot (2007, p. 95) "it is without doubt the most widely used instrument in language learner strategy research". The latter, which focuses exclusively on listening strategies, was designed to serve as a self-assessment instrument, and to assess the extent to which language learners are aware of their own processes of L2 listening comprehension (Vandergrift, 
et al., 2006). The reason why we developed our own instrument instead of using MALQ, as Vandergrift and Tafaghodtari (2010) did, is because we aimed to include all three types of strategies (metacognitive, cognitive and socio-affective) and not only metacognitive ones.

Third, we opted to include closed-ended items in which respondents were provided with ready-made response options to choose from by putting an " $\mathrm{X}$ " in the appropriate box. In this way, the respondents were required to indicate different degrees of frequency by marking one out of four categories of the scale ("always", "often", "seldom", and "never"). The points on the scale were assigned successive numbers as this simplifies their computer coding (Dörnyei and Taguchi, 2010).

Fourth, the questionnaire was written in English instead of Spanish (target language) or Cantonese (mother tongue). We decided to administer the questionnaire in English and not in Spanish with the purpose of simplifying comprehension and to minimize the tendency of students, pointed out by Dörnyei and Taguchi (2010), to express agreement with the sentences that they do not quite understand. We opted to write it in English rather than in Cantonese since the language of instruction at The University of Kong Kong is English. Additionally, in class, participants expressed their preference to learn Spanish from English rather than from Cantonese, since English and Spanish are languages much more similar than Cantonese and Spanish.

Fifth, we decided to create a structured and specific questionnaire in a way that the researcher had complete control over the questioning.

Sixth, we attempted to use simple and natural language, repeated nouns instead of using pronouns to avoid vague referents, and used specific rather than general terms. On the contrary, we avoided elements that could be ambiguous, negative constructions, questions that ask two questions in one, as well as metaphors. Additionally, we tried not to word the question in a way that it suggested that the behaviour was rather common. We also abstained from including reasons that explained the behaviour, as we consider, for instance, that the question "Watch speakers' gestures and general body language to help me figure out the meaning of what they are saying" (Cohen, Oxford, and Chi, 2002) is too explicit and, as a consequence, it may influence students' responses due to the tendency pointed out by Bakan (1954) to supply socially acceptable data.

Seventh, as our purpose was to obtain data on general strategic behaviour, we determined our questionnaire not to rely on any particular listening task.

Eighth, we put the questionnaire to the test by administering the first draft to eight Hong Kong students of Spanish with identical cultural and linguistic background as the target participants, and asked them to complete it and comment on their understanding (or lack of it) of the questions.

Ninth, we administered the questionnaire in class in order to facilitate questioning for clarification.

Table 1 shows the resulting general listening strategy questionnaire.

Once we collected replies from both initial and final questionnaires, we assigned successive numbers to the four categories of the scale. In this case, "always" was represented by number 1 , "often" by number 2 , "seldom" by number 3 , and "never" by number 4 . We then entered the replies by all participants, 3040 items in total, to IBM SPSS Statistics. With the objective of addressing our research question, based on finding out how the general strategic behaviour of each group (experimental and control) 
Table 1 General listening strategy questionnaire

Put an $\mathrm{X}$ in the column that describes the frequency (always, often, seldom, never) you use every listening strategy.

ALWAYS OFTEN SELDOM NEVER

$\begin{array}{llll}(1) & \text { (2) } & \text { (3) } & \end{array}$

Q.1 Before listening, I make sure I understand the listening activity (both objective and procedure).

Q.2 I ask the teacher for clarification when necessary.

Q.3 I decide what I am going to focus my attention on.

Q.4 I prepare for listening.

Q.5 I focus my attention on the required information to accomplish the listening activity.

Q.6 I lose my concentration.

Q.7 I refocus my attention when lost.

Q.8 I check whether what I understood is plausible or logic.

Q.9 I am satisfied with my understanding.

Q.10 I am satisfied with the outcome of the listening activity.

Q.11 I am able to complete the activity properly.

Q.12 I guess what I am going to listen next.

Q.13 I guess the speaker's attitude based on background noises, tone of voice, gestures or other clues.

Q.14 I look for words which are similar in Spanish and English.

Q.15 I remember everything I know about the subject.

Q.16 I make use of my prior knowledge about the subject.

Q.17 I remember everything I know about the text type and its structure

Q.18 I make use of my prior knowledge about the text type.

Q.19 While I am listening, I take notes.

Q.20 After listening, I take notes.

Q.21 I repeat words as I hear them.

Q.22 I speak aloud the new words.

Q.23 I quietly practice the pronunciation of new words.

Q.24 I translate word-by-word.

Q.25 I translate some ideas.

Q.26 I translate the gist.

Q.27 I make a mental summary of what I hear.

Q.28 I make a written summary of what I hear.

Q.29 I look up unknown words in the dictionary.

Q.30 I use available resources (dictionary, Wikipedia, etc.).

Q.31 I make use of my knowledge of English or any other language.

Q.32 I apply my own rules.

Q.33 I substitute words that I know to fill gaps I was not able to understand.

Q.34 I ask the speaker (or the teacher) either to repeat or to slow down when necessary.

Q.35 I ask for clarification when necessary.

Q.36 I talk to my classmate.

Q.37 I mentally answer questions made to other peers.

Q.38 I try to relax. 
Table 1 General listening strategy questionnaire (Continued)

Q.39 I encourage myself

Q.40 I believe it is possible for me to understand what I hear.

developed after the instruction, we compared initial and final means with PairedSamples T Tests.

\section{Results \& discussion}

Both the descriptive and the parametric analysis of the 3040 items collected through the presented questionnaire shed light on the typical strategic behaviour of the participants in the study.

Regarding the experimental group, results of the Paired-Samples T Test show statistically significant differences in six of the 40 items of the questionnaire, specifically, in questions 9, 10, 11, 14, 39, and 40 (see Table 2).

By comparing the initial and final means, we observe that, in all six cases, the final mean is higher than the initial one, which means a decrease in frequency of strategy used. In this regard, after the listening strategies instruction, the 19 members of the experimental group reported to be less regularly satisfied with their comprehension (Q.9), the outcomes of the listening activity (Q.10), and their ability to complete the activity properly (Q.11). They also informed to feel less self-confident regarding their ability to listen (Q.40).

Those results are specially shocking considering that the participants in the experimental group significantly improved their listening comprehension during the course of the instruction (Nogueroles López and Blanco Canales, in press). This mismatch between learners' significant gain in listening ability and the decrease in confidence about their listening ability and performance may be explained because, unlike Graham and Macaro (2008), our participants in the experimental group did not recognize this improvement themselves. This decrease in satisfaction towards listening ability and performance by the members of the experimental group might be related to the constant reflection on listening difficulties. During the semester of instruction and after every listening activity, the students in the experimental group always reflected on the processes they underwent when listening, on the difficulties they faced to understand oral messages, on the actions they carried out to minimize such difficulties, and on the effectiveness of those actions. This awareness-raising towards listening difficulties might be the cause of a decrease in satisfaction among students in the experimental group. In this regard, it could be advisable to follow Cross and Vandergrift's (2015) suggestion and thus to link the general listening strategy questionnaire to a specific listening experience, so they can easily relate their listening performance (and, in this case, success) to specific strategy use.

In terms of strategic behaviour, students in the intervention group reported to look for cognates (Q.14) less frequently than before the instruction. This reduction may mean that, as students' have improved their listening ability in Spanish, they do not need to rely on cognates. Students in the experimental group also reported to encourage themselves (Q.39) less often than at the beginning of the intervention. In fact, Cohen's $d$ show a large effect size in connection with this question, and therefore it is important to note the decrease in use of the affective strategy of self-encouragement. 
Table 2 Comparison between initial and final listening strategic behaviour by the EXPERIMENTAL GROUP. Paired sample t-test

\begin{tabular}{|c|c|c|c|c|c|c|}
\hline Question & $\begin{array}{l}\text { Mean } \\
\text { Initial-Final questionnaire }\end{array}$ & Std. Deviation & $\mathrm{t}$ & $d f$ & Sig. (2-tailed) & D-Cohen (only if $p$-value $<.05$ ) \\
\hline 1 & $1.4211-1.5789$ & .60214 & -1.143 & 18 & .268 & \\
\hline 2 & $2.2632-2.4737$ & 1.03166 & -.889 & 18 & .385 & \\
\hline 3 & 1.4211-1.6316 & .97633 & -.940 & 18 & .360 & \\
\hline 4 & $1.7368-1.5263$ & .78733 & 1.166 & 18 & .259 & \\
\hline 5 & $1.5789-1.6842$ & .87526 & -.524 & 18 & .607 & \\
\hline 6 & 2.4737-2.5789 & .65784 & -.697 & 18 & .494 & \\
\hline 7 & $1.7368-1.5789$ & .83421 & .825 & 18 & .420 & \\
\hline 8 & $1.8421-1.6842$ & 1.21395 & .567 & 18 & .578 & \\
\hline 9 & 2.2632-2.7895 & .84119 & -2.727 & 18 & .014 & .6257 \\
\hline 10 & $2.4211-2.7895$ & .68399 & -2.348 & 18 & .031 & .5386 \\
\hline 11 & $2.1053-2.4737$ & .68399 & -2.348 & 18 & .031 & .5386 \\
\hline 12 & $1.6316-1.6842$ & .91127 & -.252 & 18 & .804 & \\
\hline 13 & $1.6842-1.7368$ & .91127 & -.252 & 18 & .804 & \\
\hline 14 & $1.4737-1.7895$ & .58239 & -2.364 & 18 & .030 & .5422 \\
\hline 15 & $2.2105-2.3158$ & 1.04853 & -.438 & 18 & .667 & \\
\hline 16 & $1.8421-1.8421$ & .74536 & .000 & 18 & 1.000 & \\
\hline 17 & $2.4211-2.3684$ & .97032 & .236 & 18 & .816 & \\
\hline 18 & $1.9474-2.1053$ & .68825 & -1.000 & 18 & .331 & \\
\hline 19 & $1.7368-1.5263$ & .91766 & 1.000 & 18 & .331 & \\
\hline 20 & $2.1579-1.7368$ & 1.21636 & 1.509 & 18 & .149 & \\
\hline 21 & $2.0526-2.4211$ & 1.01163 & -1.587 & 18 & .130 & \\
\hline 22 & $2.6316-2.5263$ & 1.10024 & .417 & 18 & .682 & \\
\hline 23 & $2.4737-2.2632$ & .91766 & 1.000 & 18 & .331 & \\
\hline 24 & $2.4211-2.5789$ & 1.34425 & -.512 & 18 & .615 & \\
\hline 25 & $2.1579-2.1053$ & .91127 & .252 & 18 & .804 & \\
\hline 26 & $2.0000-2.1053$ & 1.04853 & -.438 & 18 & .667 & \\
\hline 27 & $2.0000-2.1579$ & .68825 & -1.000 & 18 & .331 & \\
\hline 28 & $2.7895-2.4211$ & 1.21154 & 1.326 & 18 & .202 & \\
\hline 29 & 2.1579-2.1579 & 1.10554 & .000 & 18 & 1.000 & \\
\hline 30 & $2.0000-1.7895$ & .63060 & 1.455 & 18 & .163 & \\
\hline 31 & $1.6842-1.7895$ & .73747 & -.622 & 18 & .542 & \\
\hline 32 & $3.0000-2.4737$ & 1.42861 & 1.606 & 18 & .126 & \\
\hline 33 & $2.0000-2.0000$ & .74536 & .000 & 18 & 1.000 & \\
\hline 34 & $2.4211-2.4211$ & 1.05409 & .000 & 18 & 1.000 & \\
\hline 35 & $2.1579-2.4211$ & 99119 & -1.157 & 18 & .262 & \\
\hline 36 & $2.4211-2.0526$ & .95513 & 1.681 & 18 & .110 & \\
\hline 37 & $1.9474-2.1579$ & .63060 & -1.455 & 18 & .163 & \\
\hline 38 & $2.1053-2.1053$ & 1.24722 & .000 & 18 & 1.000 & \\
\hline 39 & $1.6842-2.3684$ & .88523 & -3.369 & 18 & .003 & .7729 \\
\hline 40 & $1.8947-2.2632$ & 68399 & -2.348 & 18 & .031 & .5386 \\
\hline
\end{tabular}


According to Chen (2009), affective strategies could help students strengthen their own ability to cope with their fear of the unknown in the input and with the obstacles which occurred while they were performing listening tasks. As a consequence, the decrease of frequency of use of the affective strategy of self-encouragement by the members of the experimental group in our study may be related to the reduction in self-confidence.

In respect of the control group, the calculation of Paired-Samples $T$ Test reveals significance in five out of the 40 questions, specifically in questions $2,10,11,32$, and 39 (see Table 3). Like the students in the experimental group, members in the control group reported to feel less satisfied with the outcome of the listening task (Q. 10), and less able to complete the task in a proper way than at the beginning of the course. However, unlike their peers in the experimental group, this feeling may be due to the fact that their listening comprehension barely changed during the instruction (Nogueroles López and Blanco Canales, in press). It is also important to note that, unlike the experimental group, students in the control group were not familiar with listening strategies, as they did not receive any training in listening strategies. As Dörnyei and Taguchi (2010) point out, this lack of familiarity with listening strategies might took the members of the control group to agree with sentences that they did not fully understand. However, the potential effect of this unfamiliarity with listening strategies by the members of the control group could not be reduced.

Participants in the control group also informed to use the affective strategy of selfencouragement less regularly than at the beginning of the course (Q.39), and, once again, Cohen's $d$ reveals a large effect size with regard to this statement. Such a reduction in the frequency of use of the affective strategy of self-encouragement may be also linked to the decrease in satisfaction and confidence.

Unlike the experimental group and despite they did not receive any listening strategies instruction, the members of the control group did report an increase in the frequency of use of two strategies: the social strategy of asking for clarification (Q. 2), and the cognitive strategy of deduction (Q. 32). In this regard, we should bear in mind that the two times that the members of the control group completed the general listening strategy questionnaire, they reflected on the metacognitive, cognitive and socioaffective processes they experience while listening. Nevertheless, and as well as in Vandergrift and Tafaghodtari's study (2010), the potential effect of this consciousnessraising in the control group could not be minimized.

Summing up, resulting data point out modest differences in general listening strategic behaviour after the strategies instruction in both groups, the experimental and the control one. Since any minimum variation in listening processes requires prolonged and systematic attention, awareness, practice, self-assessment and reflection, we believe that the implemented instruction should be extended in time, at least for one academic year (like Thompson and Rubin, 1996). However, our study could not be any longer due to the fact that students move from one class to another from semester to semester, so, after the semester of instruction, students in the experimental group could move to the control group and vice versa. Similarly, Cross (2009) also considers that his $12 \mathrm{~h}$ of strategy instruction over the 10-week course may had been insufficient to expect the members of the experimental group to fully absorb, practice and effectively orchestrate the repertoire of strategies presented. 
Table 3 Comparison between initial and final listening strategic behaviour by the CONTROL GROUP. Paired-Samples T Test

\begin{tabular}{|c|c|c|c|c|c|c|}
\hline Question & Initial-Final Mean & Std. Deviation & $\mathrm{t}$ & df & Sig. (2-tailed) & D-Cohen (only if $p$-value <.05) \\
\hline 1 & $1.6316-1.6316$ & .74536 & .000 & 18 & 1.000 & \\
\hline 2 & $2.5263-2.3158$ & .41885 & 2.191 & 18 & .042 & .5026 \\
\hline 3 & $1.5789-1.6842$ & .31530 & -1.455 & 18 & .163 & \\
\hline 4 & $1.5789-1.5789$ & .47140 & .000 & 18 & 1.000 & \\
\hline 5 & $1.7895-1.6316$ & .50146 & 1.372 & 18 & .187 & \\
\hline 6 & $2.5263-2.5789$ & .77986 & -.294 & 18 & .772 & \\
\hline 7 & $1.4737-1.6316$ & .68825 & -1.000 & 18 & .331 & \\
\hline 8 & $1.8421-1.6316$ & .85498 & 1.073 & 18 & .297 & \\
\hline 9 & $2.5789-2.7895$ & .71328 & -1.287 & 18 & .215 & \\
\hline 10 & $2.4737-2.8421$ & .76089 & -2.111 & 18 & .049 & .4842 \\
\hline 11 & $2.0526-2.4737$ & .69248 & -2.650 & 18 & .016 & .6080 \\
\hline 12 & $1.7368-1.5789$ & .76472 & .900 & 18 & .380 & \\
\hline 13 & $1.5263-1.6842$ & .68825 & -1.000 & 18 & .331 & \\
\hline 14 & $1.2632-1.4737$ & .63060 & -1.455 & 18 & .163 & \\
\hline 15 & $2.3684-2.1579$ & .71328 & 1.287 & 18 & .215 & \\
\hline 16 & $1.8421-1.9474$ & .73747 & -.622 & 18 & .542 & \\
\hline 17 & $2.3684-2.6316$ & .80568 & -1.424 & 18 & .172 & \\
\hline 18 & $1.9474-2.0000$ & .84811 & -.271 & 18 & .790 & \\
\hline 19 & 2.0526-1.7895 & 1.04574 & 1.097 & 18 & .287 & \\
\hline 20 & $2.4211-2.1579$ & 1.19453 & .960 & 18 & .350 & \\
\hline 21 & $2.2105-2.1053$ & .56713 & .809 & 18 & .429 & \\
\hline 22 & $2.8947-2.5263$ & .89508 & 1.794 & 18 & .090 & \\
\hline 23 & $2.3684-2.2105$ & .60214 & 1.143 & 18 & .268 & \\
\hline 24 & $2.3684-2.4737$ & .65784 & -.697 & 18 & .494 & \\
\hline 25 & $1.7368-1.9474$ & .71328 & -1.287 & 18 & .215 & \\
\hline 26 & $2.0000-2.0526$ & .77986 & -.294 & 18 & .772 & \\
\hline 27 & $2.1579-2.1579$ & .57735 & .000 & 18 & 1.000 & \\
\hline 28 & $2.9474-2.6842$ & .99119 & 1.157 & 18 & .262 & \\
\hline 29 & $2.1579-2.1579$ & 1.01451 & .678 & 18 & .506 & \\
\hline 30 & $2.1579-1.9474$ & .91766 & 1.000 & 18 & .331 & \\
\hline 31 & $1.3684-1.4737$ & .45883 & -1.000 & 18 & .331 & \\
\hline 32 & $2.5789-2.0000$ & 1.01739 & 2.480 & 18 & .023 & .5690 \\
\hline 33 & $2.0000-2.1053$ & .65784 & -.697 & 18 & .494 & \\
\hline 34 & $2.0000-2.3158$ & .82007 & -1.679 & 18 & .111 & \\
\hline 35 & $2.1579-2.2105$ & .70504 & -.325 & 18 & .749 & \\
\hline 36 & $1.8421-1.6842$ & .68825 & 1.000 & 18 & .331 & \\
\hline 37 & $1.9474-2.0526$ & .93659 & -.490 & 18 & .630 & \\
\hline 38 & $1.7368-2.1053$ & .59726 & -2.689 & 18 & .015 & \\
\hline 39 & $1.7895-2.1579$ & .49559 & -3.240 & 18 & .005 & .7433 \\
\hline 40 & $2.0526-2.1579$ & .65784 & -.697 & 18 & .494 & \\
\hline
\end{tabular}




\section{Conclusions}

This article reports on an intervention study intended to explore the impact of the implemented listening strategies instruction on learners' general strategic behaviour. We planned, tested, adjusted and implemented a listening strategies instruction for an academic semester. The instruction was structured in three cycles: the first devoted to the development of the selected metacognitive strategies, the second to the promotion of the target cognitive strategies, and the third to the teaching of the chosen socio-affective strategies. Awareness and understanding of the benefits of using listening strategies and of their procedures of use, together with scaffolded practice guided by metacognition, self-assessment, and autonomous use were at the core of each one of the three cycles of instruction.

The method we designed, piloted, fine-tuned, and administered to collect data on participants' typical or general use of listening strategies was a self-reported questionnaire which, according to Cohen (1998), is the most frequently used and efficient method for discovering learning strategies. Such an instrument was tested for item comprehension, but it could have also been tested for its content validity.

Results of the study show minor changes in terms of general listening strategic behaviour after the instruction in both groups. These results are extremely valuable as they indicate that these particular students may need to devote more time to reflect on, practice, evaluate and transfer the use of listening strategies.

In addition to the results of the empirical study, the value of the present article focuses on the fact that, first, it presents detailed information about the implemented listening strategies instruction that can be applied by other language teachers. Second, it sheds light on the participants' general strategic behaviour and thus provides the teacher with useful information to adapt their teaching methods to their students' specific characteristics and needs. Third, the study also offers a ready-made self-report questionnaire that can be easily used by foreign language teachers in order to both increase understanding about their students' typical listening strategic behavior and to raise their students' awareness of their own listening strategies use.

Competing interests

I confirm that no funding was received for the presented study and that I have no competing interests in the manuscript.

\section{Publisher's Note}

Springer Nature remains neutral with regard to jurisdictional claims in published maps and institutional affiliations.

Received: 10 January 2017 Accepted: 11 June 2017

Published online: 19 June 2017

References

Bakan, D. (1954). A reconsideration of the problem of introspection. Psychological Bulletin, 51, 105-118.

Chamot, A. U. (2004). Issues in language learning research and teaching. Electronic Journal of Foreign Language Teaching, 1(1), 14-26.

Chamot, A. U., \& O'Malley, J. M. (1994). The Calla handbook: Implementing the cognitive academic language learning approach. White Plains: Addison Wesley Longman.

Chamot, A. U., Barnhardt, S., El-Dinary, P. B., \& Robbins, J. (1999). The learning strategies handbook. White Plains: Addison Wesley Longman.

Chen, A.-H. (2009). Listening strategy instruction: Exploring Taiwanese college students' strategy development. Asian EFL Journal, 11, 54-85.

Cohen, A. D. (1998). Strategies in learning and using a second language. New York: Addison Wesley Longman. Cohen, A. D. (2011). Strategies in learning and using a second language. Harlow, England: Pearson/Longman.

Cohen, A. D., Oxford, R., \& Chi, J. (2002). Language Strategy Use Survey. Minneapolis, Minnesota: Center for Advanced Research on Language Acquisition, University of Minnesota. Resource document. The Center for Advanced Research on Language Acquisition (CARLA). http://carla.umn.edu/about/profiles/CohenPapers/Lg_Strat_Srvy.html. Accessed 14 June 2017. 
Cross, J. (2009). Effects of listening strategy instruction on news videotext comprehension. Language Teaching Research, 13(2), 151-176.

Cross, J., \& Vandergrift, L. (2015). Guidelines for designing and conducting L2 listening studies. ELT Journal, 69(1), 86-89. Dörnyei, Z., \& Taguchi, T. (2010). Questionnaires in second language research. New York: Routledge.

Flowerdew, J., \& Miller, L. (2005). Second language listening: Theory and practice. New York: Cambridge University Press. Graham, S., \& Macaro, E. (2008). Strategy instruction in listening for lower-intermediate learners of French. Language Learning, 58(4), 747-783.

Graham, S., Santos, D., \& Vanderplank, R. (2008). Listening comprehension and strategy use: A longitudinal exploration. System, 36(1), 52-68.

Lotfia, G., Maftoon, P., \& Birjand, P. (2016). Learning to listen: Does intervention make a difference? The Language Learning Journal, 44(1), 107-123.

Lynch, T. (2009). Teaching second language listening. Oxford: Oxford University Press.

Macaro, E. (2001). Learning strategies in foreign and second language classroom. London: Continuum.

Martín Peris, E., \& Sans Baulenas, N. (2004). Gente, Nueva Edición, Libro del alumno 2. Barcelona: Difusión.

Nogueroles López, M., \& Blanco Canales, A. (in press). Un modelo de instrucción en estrategias: efectos sobre la competencia en comprensión auditiva. Journal of Spanish Language Teaching.

O'Malley, J. M., \& Chamot, A. U. (1990). Learning strategies in second language acquisition. Cambridge: Cambridge University Press.

O'Malley, J. M., Chamot, A. U., \& Kupper, L. (1989). Listening comprehension strategies in second language acquisition. Applied Linguistics, 10(4), 418-437.

Oxford, R. L. (1990). Language learning strategies: What every teacher should know. New York: Newbury House/Harper \& Row.

Oxford, R. L. (2011). Teaching and researching language learning strategies. Harlow: Longman/Pearson Education.

Oxford, R. L., \& Nyikos, M. (1989). Variables affecting choice of language learning strategies by university students. The Modern Language Journal, 73(3), 291-300.

Pica, T. (1991). Classroom interaction, negotiation, and comprehension: Redefining relationships. System, 19, 437-452.

Thompson, I., \& Rubin, J. (1996). Can strategy instruction improve listening comprehension? Foreign Language Annals, 29, 331-342.

Vandergrift, L. (1997). The strategies of second language (French) listeners. Foreign Language Annals, 30, 387-409.

Vandergrift, L. (2003). Orchestrating strategy use: Toward a model of the skilled second language listener. Language Learning, 53, 463-496.

Vandergrift, L., \& Goh, C. C. M. (2012). Teaching and learning second language listening. Metacognition in action. New York: Routledge.

Vandergrift, L., \& Tafaghodtari, M. H. (2010). Teaching L2 learners how to listen does make a difference: An empirical study. Language Learning, 60(2), 470-497.

Vandergrift, L., Goh, C. C. M., Mareschal, C. J., \& Tafaghodtari, M. H. (2006). The metacognitive awareness listening questionnaire: Development and validation. Language Learning, 56, 431-462.

Wenden, A. (1987). Incorporating learner training in the classroom. In A. Wenden \& J. Rubin (Eds.), Learner strategies in language learning (pp. 159-168). London: Prentice Hall International.

White, G. (2008). Listening and good language learners. In C. Griffiths (Ed.), Lessons from good language learners (pp. 208-217). Cambridge: Cambridge University Press.

White, C., Schramm, K., \& Chamot, A. U. (2007). Research methods in strategy research: Re-examining the toolbox. In A. D. Cohen \& E. Macaro (Eds.), Language learner strategies (pp. 93-116). Oxford: Oxford University Press.

Yeldham, P., \& Gruba, P. (2016). The development of individual learners in an L2 listening strategies course. Language Teaching Research, 20(1), 9-34.

\section{Submit your manuscript to a SpringerOpen ${ }^{\circ}$ journal and benefit from:}

- Convenient online submission

- Rigorous peer review

Open access: articles freely available online

- High visibility within the field

- Retaining the copyright to your article 